\title{
periferio
}

\section{LIRA DE OURO E REVOLUÇÃO MOLECULAR: APROXIMAÇÕES ENTRE UM MOVIMENTO CULTURAL DE DUQUE DE CAXIAS E OS CONCEITOS DE FÉLIX GUATTARI}

Cristiane Maria Medeiros Laia ${ }^{1}$

Secretaria de Estado de Educação do Rio de Janeiro

\section{Resumo}

A Sociedade Musical e Artística Lira de Ouro, que existe há 57 anos na cidade de Duque de Caxias - RJ, é trazida para estudo, como um exemplo dos movimentos culturais que ganham força nas periferias do Brasil nesses tempos, e despontam como espaços onde as diferenças, singularidades e alteridades de seus integrantes são valorizadas e trabalhadas. Algumas das características estruturais da Lira são apontadas como diferenciais responsáveis pelos anos em que a sociedade ( $r$ )existe ao contexto periférico em que se encontra, atuando como importante linha de fuga, produção cultural e espaço de vida social. Essas características são analisadas e uma aproximação da Lira de Ouro com os movimentos que Félix Guattari chama de Revolução Molecular é sugerida, considerando os aspectos revolucionários que ambos compartilham.

Palavras-chave: periferia; revolução molecular; Lira de Ouro

\footnotetext{
${ }^{1}$ Mestre pelo PPG Educação, Cultura e Comunicação em Periferias Urbanas - FEBF/UERJ. Bacharel e Licenciada em Educação Artística pela Universidade Federal de Juiz de Fora UFJF. Professora de Artes do Ensino Fundamental. Pesquisadora de Educação não formal em periferias urbanas.
} 


\title{
periferio
}

\author{
LIRA DE OURO AND MOLECULAR REVOLUTION: \\ APPROXIMATIONS BETWEEN A CULTURAL MOVEMENT OF \\ DUQUE DE CAXIAS AND THE CONCEPTS OF FELIX GUATTARI
}

\begin{abstract}
The Musical and Artistic Society Lira de Ouro, which has existed for 57 years in the city of Duque de Caxias - RJ, is brought to study as an example of cultural movements that are gaining strength in the peripheries of Brazil in these times, and emerge as spaces where the differences and uniqueness of its members and collectives that are, are affirmed. After two years of research, some of the structural characteristics of Lira differentials are identified as responsible for the years the company (r)exists to peripheral context in which it is, acting as a major line of flight of the space of cultural production and social life. These characteristics are analyzed and we suggest an approximation of Lira de Ouro with movements that Félix Guattari calls the Molecular Revolution, considering the revolutionary aspects they both share.
\end{abstract}

Keywords: peripheries; molecular revolution; Lira de Ouro 


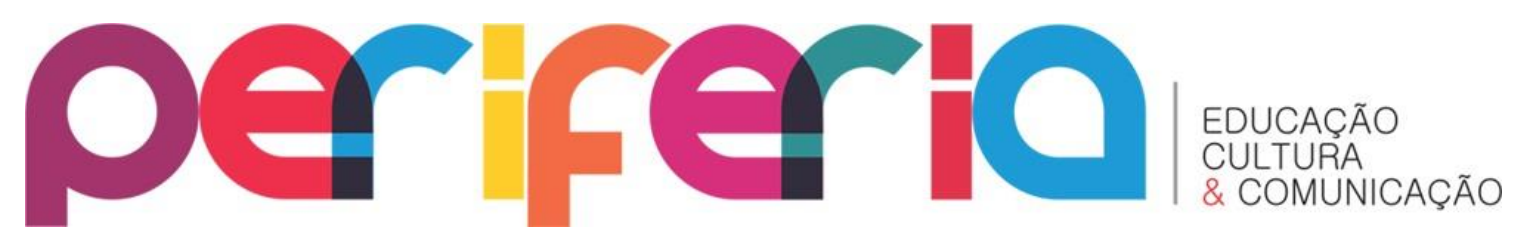

\section{A LIRA DE OURO}

Talvez até seja preciso dizer que em muitas formações sociais não são os senhores, mas antes os excluídos sociais que constituem focos de subjetivação: por exemplo, o escravo libertado que se queixa de ter perdido todo estatuto social na ordem estabelecida, e que estará na origem de novos poderes. A queixa tem uma grande importância não só poética, mas histórica e social, porque exprime um movimento de subjetivação ('pobre de mim...'): existe toda uma subjetividade elegida. O sujeito nasce nas queixas tanto quanto na exaltação (DELEUZE,1992, pp.189)

Em 12 de março de 1957, um grupo de músicos que, há alguns anos, se encontrava semanalmente para ensaios e tocatas em Duque de Caxias - RJ, fundou a Sociedade Musical e Artística Lira de Ouro. A Lira de Ouro nasceu do sonho que eles (músicos simples, pouco afamados e, na sua maioria, autodidatas) compartilhavam: levar diversão, através da música, para a camada menos abastada da cidade e fazer disso uma forma de educação na periferia.

A designação de Sociedade Artística e Musical que consta no registro formal do que, de início, era apenas mais uma Banda de Música, trouxe duas novidades. A primeira delas foi privilegiar a participação de integrantes das periferias em sua composição. A segunda foi a de abrir seu espaço a eventos artísticos e culturais de todas as naturezas.

Duque de Caxias é um dos 13 municípios que compõem a Baixada Fluminense, estado do Rio de Janeiro, Brasil, e tem hoje 873.921 mil habitantes. Apesar de ser a cidade da região metropolitana mais próxima geograficamente da capital do estado e ter o $15^{\circ}$ maior PIB do Brasil (fato que deve-se, sobretudo, às refinarias de petróleo instaladas ao longo de seus 467,619 Km quadrados de extensão territorial) ${ }^{2}$ Duque de Caxias ainda hoje

2 http://www.ibge.gov.br/cidadesat/painel/painel.php?codmun=330170. Acesso em $15 / 02 / 2014$ 


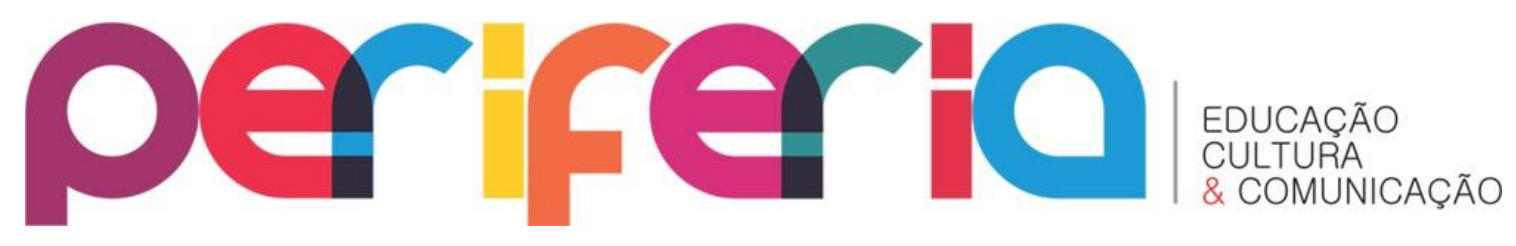

sofre com problemas básicos de infraestrutura, como a ausência de rede de esgoto em muitos bairros, ruas sem calçamento e/ou passeios e a falta semanal de abastecimento de água em algumas regiões. 0 município, que ainda funciona como cidade dormitório do Rio de Janeiro, por vezes parece todo ele uma grande periferia, dados o descaso público e a falta de políticas para melhoria das condições de vida e acesso da população.

Nos anos de 1980, quando os músicos fundadores da Lira de Ouro não tinham mais forças e meios para lutar por verbas e financiamentos para a Banda, a Sociedade passou por uma grave crise. Sua sede, comprada na década de 1960 com as economias dos próprios músicos, foi sendo abandonada gradativamente pelo poder público e pelos antigos frequentadores, a partir de então.

A ameaça da apropriação do espaço pela prefeitura da cidade, justificada por esse abandono, fez com que os artistas, professores, sambistas, músicos e intelectuais da cidade se unissem para reconstruir o espaço física e conceitualmente, a partir de meados da década de 1990. Desde então, a Lira passou a ser um espaço de convivência entre as mais variadas formas de expressão cultural e artística, e um dos centros culturais mais importantes da Baixada Fluminense. Aulas de teoria musical e dança de salão convivem (muitas vezes nos mesmos dias e espaços) com a Dança de Rua, a apresentação de músicos locais, saraus e exibições de cineclubes, onde se discute de Black Blocks à Deleuze, "bebendo Mate e comendo Angu" ${ }^{3}$. A maioria das atividades é gratuita.

O público frequentador é bem heterogêneo, composto por adultos, adolescentes e muitos jovens, que parecem sentir orgulho de dizer que fazem parte da Lira de Ouro. 0 sentimento de pertencimento e criação de sentido na feitura das atividades e na integração arte-cultura-diferença é o que mantém viva, contextualizada e atual a essência desse lugar.

\footnotetext{
${ }^{3}$ Uma referência ao cineclube "Mate com Angu", também da Baixada Fluminense, cujas exibições acontecem na Lira na última quarta-feira de todo mês. Saiba mais sobre Cineclube Mate com Angu em http://matecomangu.org/site/
} 


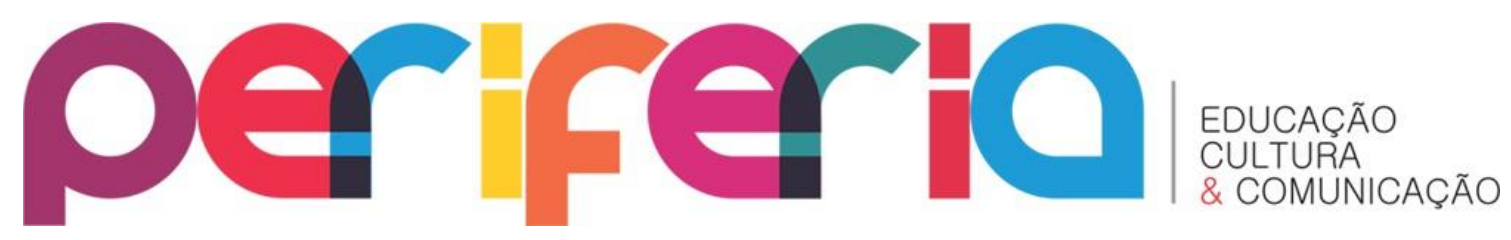

A multiplicidade e possibilidade de agregar singularidades, cujo objetivo comum é o desejo de alcançar formas mais interessantes de vida por meio da cultura, mantém de pé uma instituição, que já na década de 1950, trazia a consciência da diferença como ingrediente essencial no fortalecimento da identidade local.

\section{SOBRE O NOVO PARADIGMA ESTÉTICO DE GUATTARI}

Na década de 1970 o psicanalista francês Félix Guattari nos traz a ideia de "Um Novo Paradigma Estético"4, em uma proposta que é elaborada considerando aspectos psicológicos, sociais e políticos desses tempos, quando o capitalismo rege a lógica não só de mercado, mas da sociedade em sua completude, interferindo e definindo as relações humanas também nas esferas da sensibilidade, da criação e, logo, da subjetivação. O Novo Paradigma Estético "se apresenta como uma alternativa em relação ao paradigma científico subjacente ao universo capitalista” (GUATTARI, 1993, pp.29). É o Paradigma da Criatividade como alternativa aos Paradigmas adotados até então no Ocidente, onde só tardiamente a arte destacou-se como atividade específica, o que levou a secundarização da importância da sensibilidade (estética, perceptiva e criativa) nas relações sociais e humanas.

Esse novo paradigma seria então uma nova forma que atingiria o pensamento, o comportamento, as atitudes, as escolhas e a vida em todos os âmbitos.

Uma das principais ideias desse paradigma, diz respeito à subjetividade e à expansão que o autor faz desse conceito. Guattari abandona a ideia do marxismo clássico, onde a subjetividade era um elemento da superestrutura ideológica, e considera que ela se faz não só pelos meios clássicos que se acreditava antes (figura do pai e da mãe como eixo de construção do sujeito, por exemplo), mas por todas as coisas que permeiam e transpassam a 


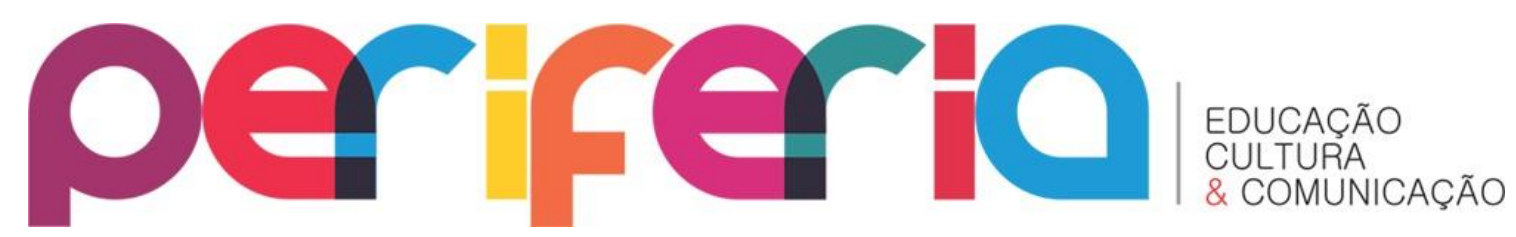

existência humana: a produção de subjetividade tem como atores também a TV, o cinema, a mídia de forma geral, as conversas com amigos, as discussões políticas e de todos os temas possíveis, a convivência com vizinhos, as viagens, as leituras de jornais, livros,... Tudo isso produz inconsciente, o que faz com que sejamos vários, múltiplos e plurais no que nos existe de mais singular. Guattari sublinha: "a categoria 'produção de subjetividade' substitui, para mim, a oposição entre o sujeito e o objeto" (GUATTARI, 1993, pp.31). E conclui que

subjetividade é o conjunto das condições que torna possível que instancias individuais e/ou coletivas estejam em posição de emergir como território existencial auto referencial em adjacência ou em relação de delimitação com uma alteridade ela mesma subjetiva. (GUATTARI, 2006, p.19)

Nessa mesma lógica, esse autor, em parceria com Deleuze, nos traz a ideia de máquina e estende esse conceito para os outros setores da vida. Eles consideram que esse conceito é mais apropriado para traduzir as organizações da sociedade de então, que o conceito de estrutura (mais engessado) usado até o momento em questão. Visto que pode incluir tanto formas mais maleáveis de organização quanto aquelas mais tradicionais. Para os autores

o maquínico (que é o contrário do mecânico) é processual, produtivo, produtor de singularidades, de irreversibilidades, e temporal. Nesse sentido ele se opõe, termo a termo, à ideia de estrutura, de intercambialidade, de homologia, de equilíbrio, de reversibilidade, de a-historicidade etc. (PELBART,1993, p.44)

Essa substituição proposta condiz com a lógica de pensamento do novo paradigma, em que as subjetividades não são mais entendidas como construções solitárias e nem fazem mais parte da superestrutura ideológica, mas constituem e são constituídas pelos mais diversos grupos (maquínicos, individuais e coletivos) no seio dessas máquinas/ organizações. 


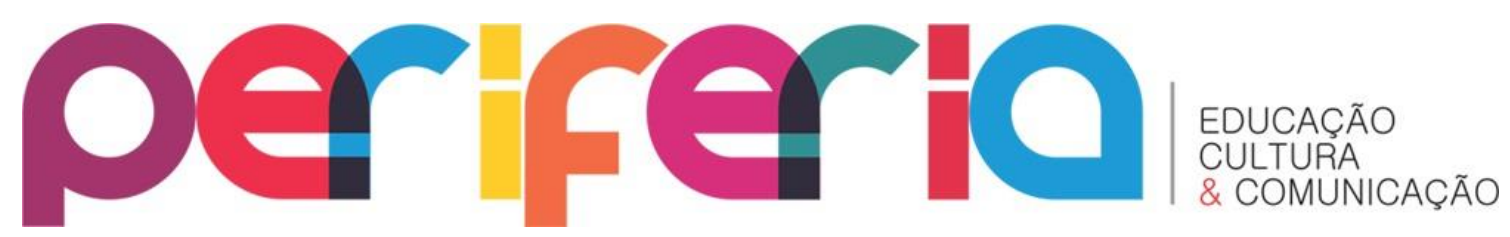

Com a ideia de máquina estendida, estende-se também a ideia de produção, que passa a fazer parte de todos os níveis, inclusive do desejo e do inconsciente.

produção não é só produção de coisas materiais e imateriais no interior de um campo de possíveis, mas também produção de novos possíveis, quer dizer, produção de produções, de bifurcações, de desequilíbrios criadores, de engendramentos a partir de singularidades, autoposicionamentos, autopoiese. Pela autopoiese algo se desdobra, ganhando consistência, autonomia, um movimento próprio, formando um universo a partir de seus componentes, se existencializando e até, no limite, tecendo uma subjetivação própria. (GUATTARI, 1993, p.44 e 45)

Produções essas que se dão no interior das máquinas mais maleáveis, aquelas de organização celular, possibilitadoras de combinações, criadoras de linhas de fuga, desterritorializadas e, por tudo isso, subversivas: as máquinas de guerra. Que trazem a guerra em uma outra perspectiva.

As Guerras em que as Máquinas de Deleuze e Guattari atuam, não são as guerras clássicas cujas definições nos levam, invariavelmente, à violência, seja ela física ou psicológica. São Guerras no sentido mais revolucionário que a palavra tem, são guerras no sentido de serem movimentos que contestam o que se tem definido como padrão, e buscam novas formas de entender o que antes só poderia ser entendido de um jeito. São guerras porque significam resistência ao que é imposto, questionamento ao que foi instaurado previamente sem discussão. Guerras que atuam no âmbito do pensamento, promovendo mudanças e revoluções tão grandes ou maiores que as guerras onde se derramam sangue e vida. São guerras cujos resultados são inversamente proporcionais às perdas das guerras tradicionais, onde ganha-se o direito de tomar conta do estúdio da realidade, de tomar das mãos daqueles que estão inventando a realidade para todos, a possibilidade de cada um inventar a sua própria realidade. 


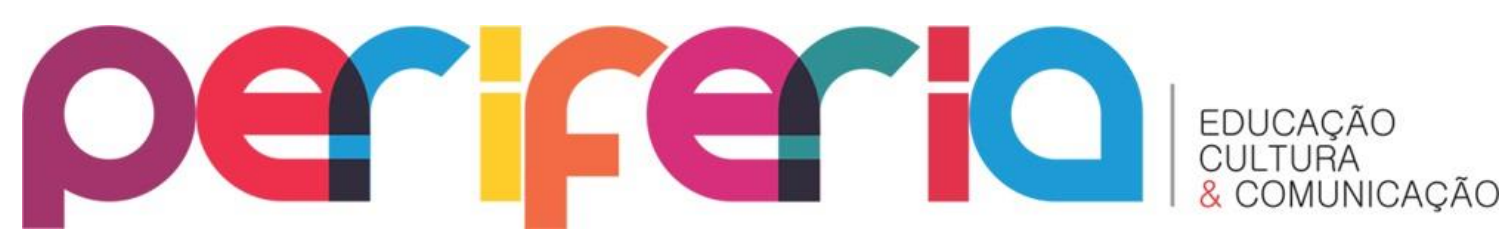

Máquina de Guerra é tudo aquilo que, pela sua forma de organização menos burocratizada e menos engessada que as formas tradicionais, coloca em xeque essas tais formas tradicionais, promovendo o questionamento e a crítica acerca de sua soberania sobre as demais formas. E muitas vezes essas guerras usam dos instrumentos do próprio sistema que estão criticando, para criticá-lo, em um processo antropofágico. Abalam, por isso, toda uma estrutura engendrada dentro de uma lógica pré-estabelecida que, no caso, é o sistema capitalista. E são elas que promovem o que Guattari conceitua Revolução Molecular. "Uma máquina de guerra pode ser revolucionária, ou artística, muita mais que guerreira" (GUATTARI, 1992, p.47)

Para Guattari (1987), à época da elaboração desses conceitos, o fato do sistema capitalista trabalhar para a manutenção das diferenças sociais existentes e, com isso, impor, entre outras coisas, a pasteurização das singularidades e alteridades do sujeito, gerariam conflitos que ultrapassariam as lutas sociais - então realidade em boa parte do mundo ocidental escancarando a insatisfação da população com o sistema capitalista, que já dava sinais há várias décadas. Esses conflitos teriam como seus agentes as máquinas revolucionárias, as máquinas de guerra que, àquelas alturas, já eram gestadas em algum lugar e de alguma forma que ainda não era conhecida - provavelmente no interior desses movimentos que já tomavam o mundo e, sobretudo, nas áreas periféricas das cidades, que cresciam em passos largos. Esses conflitos se dariam por meio de "lutas relativas às liberdades, de novos questionamentos da vida cotidiana, do ambiente do desejo, etc..." (GUATTARI,1987, p.221) - formas que agrupou no registro de "revolução molecular".

Ninguém é capaz de definir, hoje, o que serão as futuras formas de coordenação e organização dos futuros movimentos revolucionários, mas o que parece evidente é que implicarão, a título de premissa absoluta, no respeito à autonomia e à singularidade de cada uma de suas componentes. (GUATTARI, 1987, p.222) 


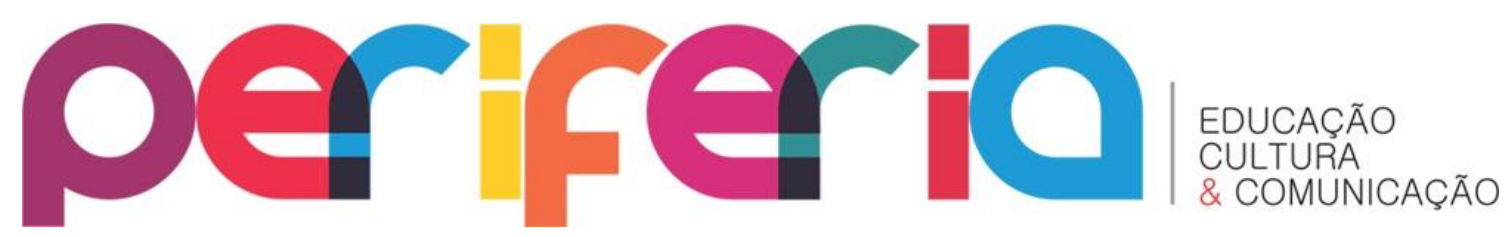

Nesse ponto trazemos as periferias para essa análise, levando em conta sua histórica presença na linha de frente de boa parte das revoluções sociais que acontecem mundo afora. Os espaços periféricos das cidades agrupam as maiores desigualdades sociais nos centros urbanos. Logo, configuram-se como espaço propícios ao surgimento de movimentos de resistência ao sistema e de busca por formas menos excludentes de vida. Assim, também nesses movimentos revolucionários de que Guattari nos fala, podemos considerar a forte presença de atores sociais que vivem nesses espaços, visto que as periferias são, além de tudo o que foi dito, uma realidade global e não só local.

Ao mesmo tempo em que são específicas de cada lugar onde se localizam geograficamente, as periferias refletem e significam, de certa forma, qualquer periferia do mundo: pessoas aglomeradas que, por definição social, vivem às margens da sociedade, nos lugares menos privilegiados, com as condições de vida menos favorecidas. Os excluídos dos lucros do sistema, a base da pirâmide que sustenta o capitalismo, os pequenos números: as minorias étnicas, culturais e sociais espalhadas mundo afora.

Podemos considerar que as periferias aglomeram um grande número de pessoas que podem, a qualquer momento, deixar de ser fracas e se tornar organizadas e perigosas. Ora pela violência e criminalidade, ora por sua cultura e sua forma peculiar de entender o mundo, há algumas décadas as periferias conseguem se impor no cenário cotidiano e na lógica da organização das cidades.

Essa segunda forma de imposição das periferias na vida da cidade é que se torna realmente "perigosa" para a manutenção da ordem social capitalista pré-estabelecida, porque é uma das formas de Revolução Molecular. Ao contrário do que acontece quando essa imposição se dá por meio da violência e da criminalidade, quando ela se dá por meio de proposições subjetivas, sai do óbvio e desmorona a "defesa”, acostumada a ter nesses primeiros atos a “justificativa” para a exclusão e a depreciação física e psicológica de seus autores. 


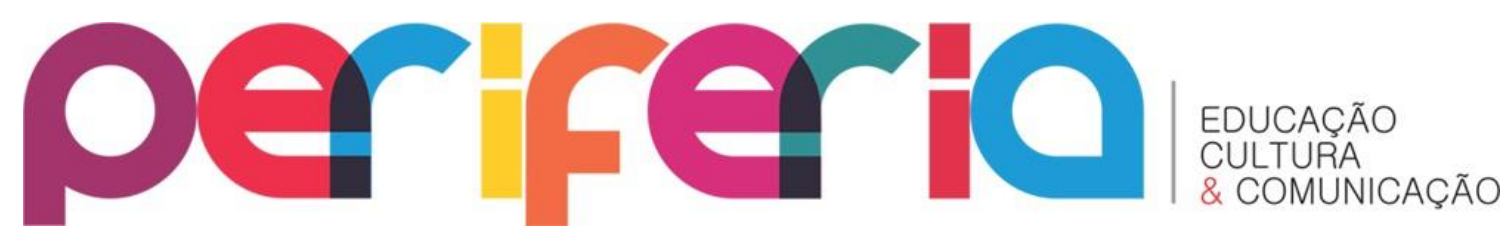

É nesse momento que a comunidade vista como necessitada econômica e politicamente de ajuda externa e, portanto, aberta aos modernos processos de "colonização cultural" vindos de fora, deixa de se posicionar como tal e passa a se comportar como agente das mudanças e melhorias de que necessita. Passa de carente a querente em um processo em que a própria lógica de centro e periferia é questionada e, algumas vezes, reconfigurada.

Quando os moradores das comunidades, favelas e guetos tomam ciência de que suas formas de entender, significar e se apropriar do mundo são próprias, peculiares e integram a construção cultural de toda uma sociedade, as periferias ganham espaço pelo que realmente são e pela força de vida que emanam, fugindo dos pastiches e cenários fakes feitos para diversão e inserção "antropoturistas" (palavra que uso para designar os turistas que vão pras favelas atrás de experiências antropológicas com os "diferentes").

Podemos dizer que esse processo, gestado pelas periferias ao longo de séculos de existência, emanam uma identidade que não se constituiu da noite para o dia e acontecem ao mesmo tempo em várias periferias do mundo todo. Esse trabalho inicia um processo de conscientização do lugar das periferias no mundo e tende a levá-las de pequeno número fraco e sem voz ativa a uma rede organizada e poderosa. Assim, interligadas propositalmente ou não essas redes vão constituindo novas formas de pensar o mundo com agentes e ações que ainda não eram colocados na grande roda. Esses são os agentes das Revoluções Moleculares, esses são máquinas de guerra por sua potência de mudança.

As máquinas de guerra são todos os periféricos, as minorias que lutam mundo afora, cada grupo à sua maneira, para mudar a sua realidade. E promovem Revoluções Moleculares, a medida que, atuando pontualmente, colaboram com o todo na "criação de máquinas revolucionárias políticas, teóricas, libidinais, estéticas, capazes de acelerar a cristalização de um modo de organização social menos absurdo que o atual”. (GUATTARI, 1987, p.225)

A forma com que essas máquinas/potências são gestadas $e$ desencadeiam as Revoluções Moleculares nos aproximam das ações da 


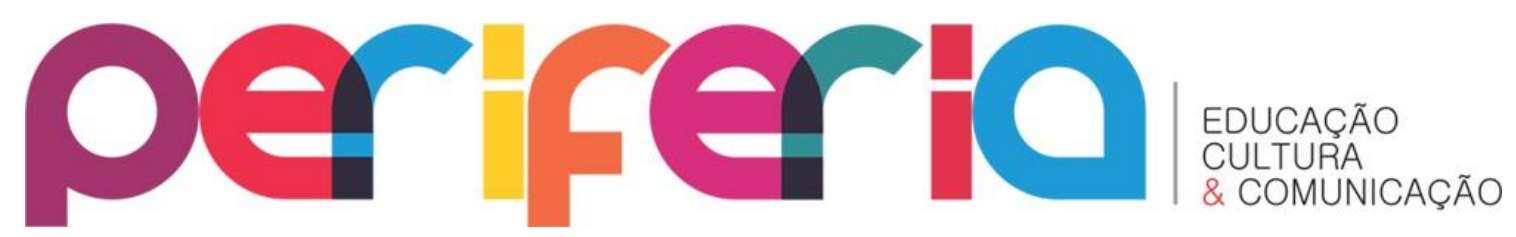

Sociedade Musical e Artística Lira de Ouro de Duque de Caxias, que serão analisadas no próximo tópico.

\section{SOBRE O OURO, A LIRA E SUAS FORMAÇÕES MOLECULARES}

Nessa análise, em que aproximamos a atuação da Lira de Ouro dos conceitos trabalhados por Deleuze e Guattari, três características dessa Sociedade são tomadas como pontos fundamentais para balizar esse pensamento.

A primeira característica refere-se à raiz conceitual da Lira de Ouro, sua origem na periferia e sua postura de resistência no contexto duquecaxiense (tanto da década de 1950 quanto dos dias de hoje).

Em uma de suas entrevistas, o Sr. Acácio ${ }^{5}$ (único dos cinco fundadores ainda vivo à época da pesquisa) contou que nos clubes da alta sociedade, onde tocavam as grandes orquestras regionais, e onde eles, os músicos menos afamados, raramente iam, era proibido o acesso de não-sócios, de negros e de pessoas que não usassem sapatos. E que existia na cidade uma divisão social geograficamente marcada pela linha do trem. Do lado da linha onde ainda hoje situa-se o bairro 25 de agosto, moravam as pessoas mais privilegiadas social e economicamente, e haviam os grandes clubes, como o Clube dos 500 . Do outro lado da linha, a parte mais baixa da cidade, afetada por enchentes e cuja maioria das ruas não tinham rede de esgoto, morava a população mais pobre, que usava o trem diariamente para ir ao trabalho - momento em que viam de relance o outro lado da linha. Essa população não tinha acesso à diversão que acontecia do outro lado, que no início dos anos 1950, já tinha uma Banda de Música - instituída como a banda oficial de Duque de Caxias formada por médicos, políticos e empresários.

A Lira de Ouro foi criada do lado mais pobre da cidade para dar diversão a quem não podia pagar por isso. Era formada por pessoas de vida

\footnotetext{
${ }^{5}$ Entrevista de Acácio de Araújo em http://www.youtube.com/watch?v=vk7JVZxm2_c
} 


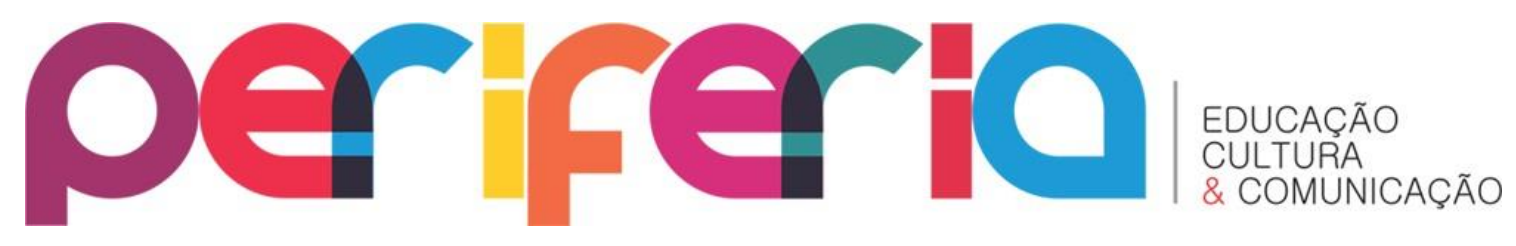

simples, trabalhadores da construção civil, da empresa telefônica, e por um protético, que se tornou o mentor da banda por seu acesso social mais fácil aos comerciantes locais e aos órgãos públicos da cidade. Aos poucos a Banda Lira de Ouro ganhou fama pelas tocatas em coretos, em festas cívicas, quermesses e em praças, onde a preferência era pelas músicas populares e pelos sucessos que estouravam nas rádios.

Da Banda que existia do outro lado da linha do trem, a Lira se apropriou apenas das convenções que regem a formação de qualquer Banda cívica (número mínimo de instrumentos e peças, um maestro, um integrante com conhecimento teórico suficiente para transcrever as partituras para vários instrumentos, etc), e de algumas poucas referências relativas ao mundo da música. Todos os demais elementos organizacionais foram introduzidos na sociedade de acordo com os próprios referenciais estéticos, culturais e musicais dos integrantes da Lira, que faziam também parte desse público periférico para o qual a Banda se voltava.

A Banda do "lado pobre" da cidade foi criada nos moldes que atendiam àquela população, nas condições financeiras possíveis aos integrantes de vida simples e luta diária, com repertórios inteligíveis por pessoas de pouco ou nenhum estudo e sabedoria construída na escola da vida. Assim, a Lira de Ouro, como Banda, foi uma construção que aconteceu da forma possível aos pequenos números que se abarrotavam na periferia da periferia (Caxias como periferia do Rio, visto que para cá vinham todos e tudo o que não cabia na capital; o lado de cá da linha do trem como a periferia de Caxias, onde sequer as condições básicas de sobrevivência eram garantidas aos moradores), e por isso configura um movimento de resistência na Baixada Fluminense.

Quando a Banda, depois de anos de ensaios informais, foi registrada em cartório e os comerciantes locais começaram a incentivar e patrocinar as tocatas e instrumentos, o poder público "enxergou" a Lira e deu-se conta da importância dessa organização para a sociedade de Duque de Caxias. E, em uma postura que, acredito passar pela necessidade de conhecer o que tanto encantava e enchia de sonhos o lado "pobre" da cidade, ou mesmo em uma 


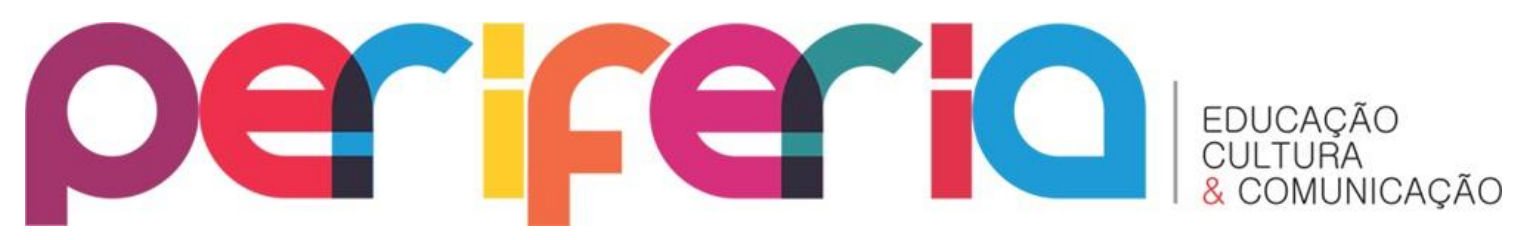

atitude de mero oportunismo político e eleitoral, integrou a Lira nos eventos cívicos de Caxias.

O fato é que, enquanto todos "viam a Banda passar", a Lira tornava-se, cada vez mais, uma arma política e por isso, revolucionária. Porque, criada nos padrões da periferia, embora patrocinada pela prefeitura em tocatas e eventos, a sociedade não abandonara seus alunos nem o trabalho voluntário de ensinar música, que logo foi ampliado para capoeira e outras atividades também gratuitas.

Como a sociedade foi criada sob os moldes de quem a criou, ela já nasceu com autonomia em relações a padrões exteriores, fator que constitui sua própria lógica de organização. Não foram poucas as tentativas de enquadrar a sociedade em algum programa, ou lei, ou negociação que a tornasse instrumento público de ação governamental. Tantas foram também as vezes em que as investidas não obtiveram êxito, ou obtiveram êxito momentâneo e, em seguida, as propostas decaíram ou caíram em desuso e esquecimento.

Como exemplo disso, podemos retomar à época em que a prefeitura buscava meios legais de se apropriar do espaço que se encontrava abandonado, e foi impedida por uma ação popular conjunta de revitalização da Lira. Os episódios de doações de uniformes pela prefeitura, de patrocínio de tocatas, de incorporação da Banda nas festas cívicas, de ajudas individuais de candidatos também podem ser vista como tentativas de ligar o nome e a atuação da Lira de Ouro a movimentos da política local, que não duraram mais que um tempo determinado. Assim como a interligação entre os integrantes da sociedade, a camada política e os cargos públicos do município, que perduram até os dias de hoje, embora aceitos e levados para dentro da Lira, nunca mudaram o fato da sociedade ser capaz de se manter e ampliar suas ações a despeito dessas "ajudas" politiqueiras, que não significam nada além de uma contribuição como qualquer outra da natureza que for. 


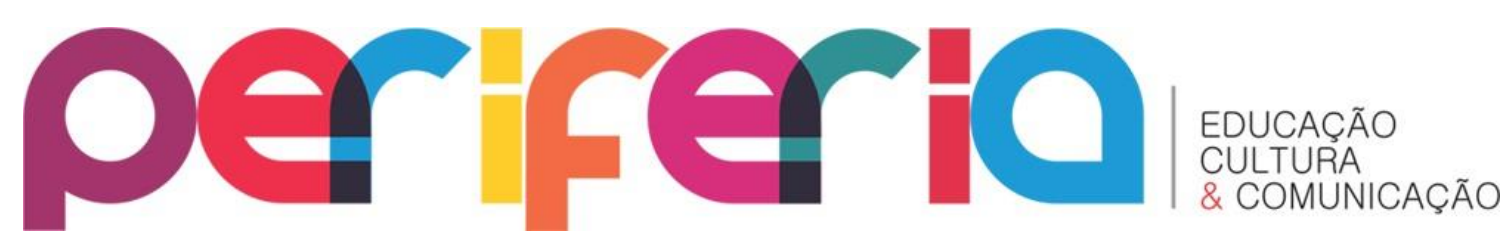

Porque a Lira é, na verdade, um movimento cuja importância primeira reside no fato de ser autônomo e independente das instâncias institucionais, às quais até ignora. Um movimento que por sua natureza vale por si mesmo enquanto potência, ação, afirmação.

Isso leva-nos a conceituar a Sociedade Musical e Artística Lira de Ouro mais uma vez como movimento de resistência e, consequentemente, uma Máquina de Guerra!

Para exemplificar isso, vamos tomar outra característica da sociedade que refere-se à gratuidade das atividades.

Desde a criação até os dias de hoje, a grande maioria das atividades na Lira de Ouro é gratuita para os participantes. Isso não quer dizer que todos os proponentes de atividades trabalham pelo regime de voluntariado. Programas e leis de incentivo a cultura são acessadas pelos proponentes dos trabalhos, tendo a Lira como um ponto de referência para a realização de projetos. Sendo a Lira financeiramente beneficiada ou não, os participantes não pagam pelo acesso às atividades.

Aula de música gratuita foi uma das primeiras preocupações do grupo de amigos que formou a Banda. Além de despertar o “gosto" pela música nas gerações mais jovens, queriam contribuir com o ensinamento de algo que pudesse se tornar uma profissão para quem estivesse entrando na vida adulta - preocupação que antecede em décadas as iniciativas governamentais voltadas para a profissionalização de jovens na Baixada Fluminense, e constitui mais uma característica revolucionária molecular do projeto. Eles acreditavam também ser essa uma forma de perpetuar a existência da banda. Perpetuando sua existência, perpetuariam também o ensino gratuito de música, multiplicando os agentes colaboradores desse trabalho.

Pela origem simples dos integrantes da banda, eles se preocupavam também em proporcionar diversão gratuita para quem não podia pagar por isso. As tocatas eram patrocinadas, mas a população não pagava para assistilas, já que grande parte dessas apresentações acontecia ao ar livre. Em épocas em que a sede da sociedade, por motivo de mudanças ou mesmo 


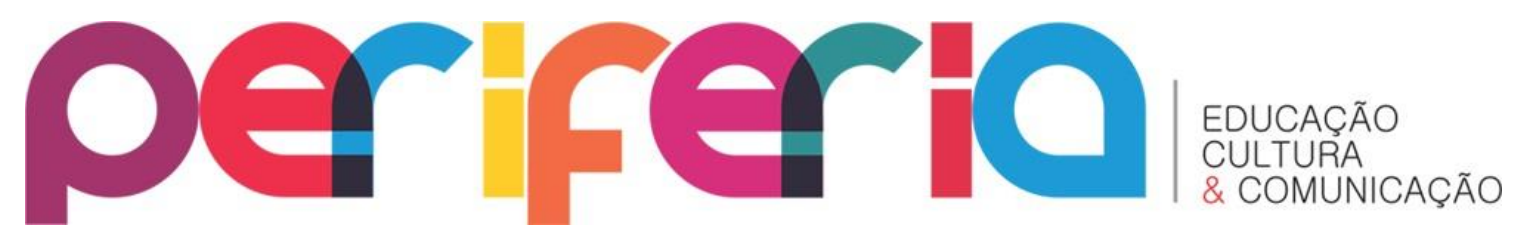

algum problema estrutural, estava impossibilitada de receber os músicos para os ensaios, esses aconteciam nas praças e até no calçadão do centro de Duque de Caxias, como forma de promover uma aproximação mais fluida com a comunidade.

O fato de não se pagar por atividades que, a rigor seriam pagas, a menos que fossem formas assistencialistas forjadas pelos governos (o que não é), faz da Lira uma máquina de guerra, atuando a contra-pelo da lógica do sistema capitalista.

Assim, embora em muitos momentos as atividades sejam patrocinadas por órgãos públicos, ajudas políticas sejam aceitas e um movimento de trocas de interesse (mesmo que a Lira não seja o foco das vantagens) seja verificado, - que importa observar é que todas essas tentativas de simular uma padronização, um enquadramento e mesmo uma dependência financeira e conceitual da sociedade em relação à qualquer instância pública ou privada, tem sua lógica invertida.

A terceira característica é referente à natureza das produções que se desenvolvem no interior da Lira. Quando ela foi criada em 1957, embora tivesse na banda de música sua principal atividade, já trazia em seu registro a possibilidade de agregar, em sua sede, várias atividades culturais e artísticas de outras naturezas. Essa atitude pode ser considerada de vanguarda. No contexto da década de 1950 as bandas de música, mesmo que formadas nas periferias, já eram consideradas parte da cultura oficial de um lugar. As demais expressões artísticas vindas do gueto, no entanto, eram tidas apenas como formas de diversão daqueles que não tinham acesso à cultura oficial. Criar um espaço aberto a tudo isso, sem distinção do que é e do que não é considerado oficial, só foi possível porque a Lira foi criada no gueto, sob os moldes do gueto, onde essas manifestações não oficiais se davam ao mesmo tempo em que a Banda passava.

Logo, ao mesmo tempo em que a criação da Lira de Ouro, como um espaço multicultural, significou a busca por entretenimento de formas diversas, configurou o nascimento de um movimento de resistência. Ainda que 


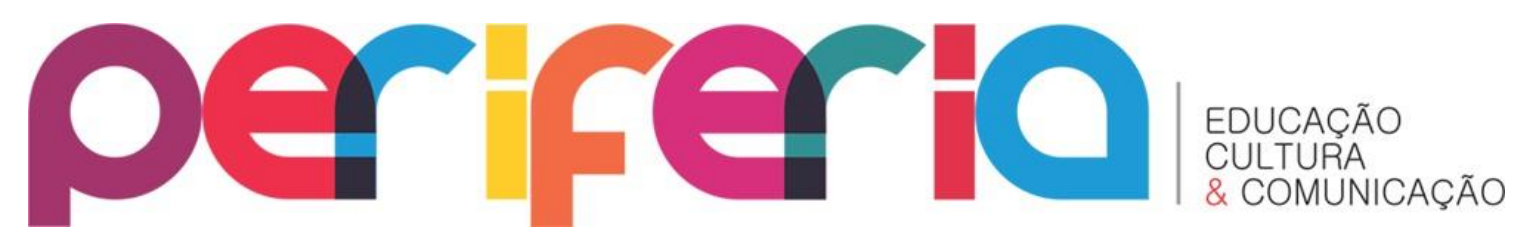

seus fundadores, à época, não tivessem a dimensão da importância dessa atitude - sobretudo na construção da subjetividade de todos os envolvidos na proposta naquele momento e em todos os outros da Lira - sabiam que criavam algo diferente e nunca visto antes na cidade, que beneficiaria a população até então excluída dessas iniciativas, e que garantiria o acesso da camada menos favorecida, econômica e socialmente, à arte. A busca coletiva pela diferença, pelo singular, em um contexto de exclusão configura o que Guattari chama de revolução molecular.

Essa abertura da Lira ao desenvolvimento das artes de todas as naturezas está diretamente ligada à produção que se configura no seio desse movimento e que nos aproxima, nessa análise, do trabalho imaterial.

Temos aqui o trabalho imaterial no sentido de trabalho vivo, aquele que é feito, antes de mais nada, por se tratar de algo em que se acredita, algo que tem um significado na vida de quem o executa, que ultrapassa as questões financeiras e econômicas e configura mesmo uma forma de existir.

0 trabalho imaterial é biopolítico na media em que se orienta para a criação de formas de vida social; já não tende, portanto, a limitar-se ao econômico, tornando-se também imediatamente uma força social, cultural e política. Em última análise, em termos filosóficos, a produção envolvida aqui é a produção de subjetividade, a criação e a reprodução de novas subjetividades na sociedade. Quem somos, como encaramos o mundo, como interagimos uns com os outros: tudo isto é criado através dessa produção biopolítica e social (HARDT e NEGRI, 2005, p. 100 e 101)

Nos tempos de sua fundação, e por cerca dos vinte e poucos anos que se seguiram, embora as atividades da Lira se limitassem às aulas de música e às apresentações, e embora os resultados desse trabalho ainda permitissem estabelecer uma lógica que se encaixava na lógica do sistema - quando ensinava-se música para pessoas que se interessavam, e muitas delas se tornavam músicos profissionais e faziam daquilo que aprenderam ali, uma profissão, uma forma de ganhar a vida - o trabalho imaterial já existia. Pode- 


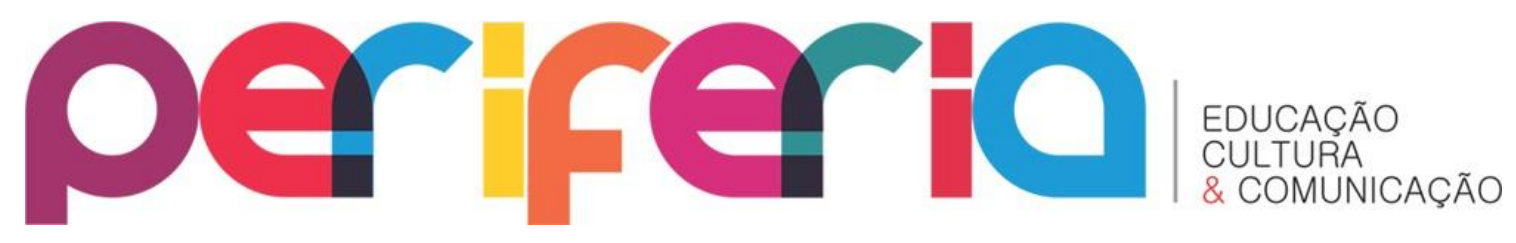

se dizer até que o trabalho imaterial existia antes mesmo da fundação da Lira e foi o que impulsionou os cinco amigos a criarem uma sociedade musical e artística em um contexto que, à rigor, deveria lutar por questões de cunho muito mais práticos que a arte.

O fato do trabalho imaterial ser componente fundamental na criação da Lira pode ser entendido também como um dos principais motivos que fez com que essa sociedade se mantivesse de pé até os dias de hoje. Quando, nos anos 1990, a Lira precisou ser reestruturada, foi por meio do trabalho imaterial dos ativistas culturais e artistas da Baixada Fluminense, que a sociedade expandiu sua atuação para as artes de outras naturezas e não foi transformada em órgão público municipal.

Com tudo isso e com a chegada da diversidade, do novo, do diferente e do múltiplo, as características de trabalho imaterial acentuaram-se. Fica evidente que, o interesse em manter o espaço vivo e desvinculado de órgãos públicos, configura uma atitude de mantê-lo desvinculado da lógica do sistema que engessa as relações das pessoas entre si e suas produções culturais. Fica evidente que acredita-se nesse espaço como um lugar de fruir cultura apenas pelo prazer de fazê-lo. Ficam evidentes as relações de afeto que a cidade e seus atores já criaram com o lugar.

Certas características do trabalho imaterial, que tendem a transformar outras formas de trabalho, apresentam um enorme potencial para a transformação social positiva. (...). Em primeiro lugar, o trabalho imaterial tende a sair do mundo limitado do terreno estritamente econômico, envolvendo-se na produção e na reprodução geral da sociedade como um todo. A produção de ideias, conhecimentos e afetos, por exemplo, não cria apenas meios através dos quais a sociedade é formada e sustentada; esse trabalho imaterial também produz diretamente relações sociais. (HARDT e NEGRI, 2005, p.101)

O que se produz na Lira, são muito mais afetos, subjetividades e redes de cooperação, agenciamentos coletivos de enunciação, que qualquer outra coisa material ou não, porque não se trata mais da 


\section{periferio}

produção de coisas materiais ou imateriais no interior de um campo de possíveis, mas também de produção de novos possíveis, quer dizer, produção de produções, de bifurcações, de desequilíbrios criadores, de engendramentos a partir de singularidades, autoposicionamentos, autopoiese. Pela autopoiese algo se desdobra, ganhando consistência, autonomia, um movimento próprio, formando um universo a partir de seus componentes, se existencializando e até, no limite, tecendo uma subjetivação própria. (GUATTARI, 1993, p. 44)

Retomando aqui o conceito de subjetividade que Guattari nos traz, temos então a Lira como movimento importante na subjetivação dos caxienses que encontram nela a possibilidade de criação e expansão de novas linhas de fuga, mais interessantes, diversas, múltiplas e revolucionárias!!!

\section{CONSIDERAÇÕES FINAIS}

A Lira é um dos muitos exemplos que o Brasil tem de iniciativas populares que, há algumas décadas, tem ganhado visibilidade por seus resultados positivos, ora no âmbito das produções materiais, ora - e muito mais - no rol das produções imateriais. E sempre por suas produções de possibilidades...

Após as formulações teóricas e análises da Lira de Ouro como movimento de resistência na Baixada Fluminense, podemos dizer que as características que ela traz e que são elementos estruturais de sua formação citadas anteriormente - são os grandes responsáveis pela sua atuação no cenário de Duque de Caxias e região, e por sua (r)existência nesses mais de 50 anos. A presença constante do trabalho imaterial (no sentido de trabalho vivo) em seu percurso, considero ser, no entanto, o que realmente faz com que as outras características não sucumbam ao tempo e às mudanças conceituais que ele traz.

A ausência da atuação do poder público em diversos setores da sociedade duquecaxiense, funcionou na época da criação da Lira, como um 


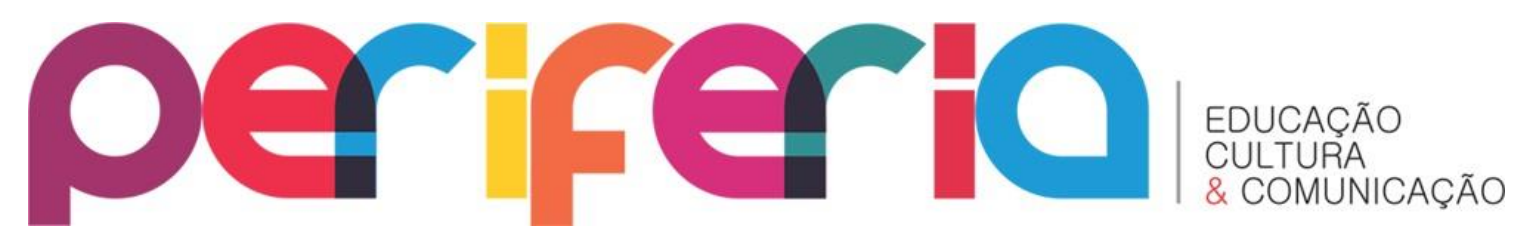

estopim para uma iniciativa que, ao longo de toda sua história, não se liga e nem depende de instâncias governamentais para se manter atuante. Essa ausência foi subvertida e transformada em força produtiva, a partir do momento (e cada vez mais) em que a Lira decidiu atuar e resistir a despeito disso. Esporádicos incentivos financeiros do poder público, no entanto, são aceitos na medida em que qualquer incentivo dessa natureza é bem-vindo, o que não significa uma ligação ou um compromisso com os valores de quem o faz. A sociedade é válida por si mesma, como movimento forte e independente, revolucionário, mais preocupado em produzir conhecimento e atuar culturalmente, que questionar ou desqualificar o que the é ausente. Uma Máquina de Guerra conceitual, estética e cultural!

Em relação à importância desse movimento para o lugar em que se formou e atua até os dias de hoje, a Lira aparece como uma potência de formação de linhas de fuga em um contexto árido de possibilidades dessa natureza. Abrigar singularidades, alteridades e diferenças na periferia da periferia, incentivando a produção cultural em um contexto em que a injustiça social ainda constitui uma constante, e transformando tudo isso em força produtiva, soa como resistência. E, por isso, se configura como um movimento de transformação social, ao qual Guattari chama Revolução Molecular.

Assim, posso dizer que a Lira é um movimento dentre os muitos que se formam e atuam no Brasil, em que o potencial criador do sujeito periférico é o motor que transforma ausências em presenças, faltas em somas, carências em querências. Um exemplo de que realmente

Cabe a cada um de nós apreciar em que medida - por menor que seja - podemos contribuir para a criação de máquinas revolucionárias políticas, teóricas, libidinais, estéticas, capazes de acelerar a cristalização de um modo de organização social menos absurdo que o atual." (GUATTARI, 1987, p.225) 


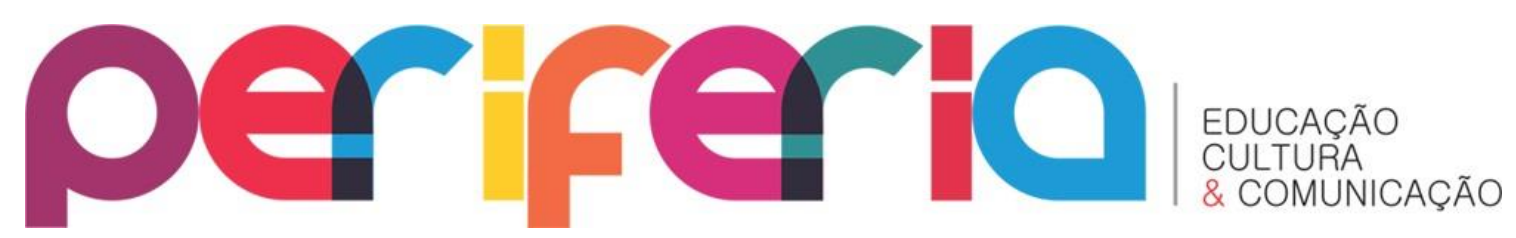

\section{REFERÊNCIAS BIBLIOGRÁFICAS}

ACÁCIO DE ARAÚJO. Entrevista concedida a Arthur William. Duque de Caxias, 20/12/2012. Disponível em:

http://www.youtube.com/watch?v=vk7JVZxm2_c;

http://www.youtube.com/watch?v=h_nXqpqjVGU;

http://www.youtube.com/watch?v=wXXwN862i98;

http://www.youtube.com/watch?v=ZqACKu0GByc. Acesso em: 17/07/2013

CAUQUELIN, Anne. Arte contemporânea: uma introdução. São Paulo: Martins Fontes, 2005 (1992). $168 \mathrm{p}$.

CINECLUBE MATE COM ANGU. Site do. Duque de Caxias. Disponível em: http://matecomangu.org/site/ Acesso em 13/02/2014

DELEUZE, Gilles. Conversações. Tradução de Peter Pál Pelbart. São Paulo: Ed. 34, 1992 - 232 p. (Coleção Trans)

DELEUZE, Gilles; GUATTARI, Felix. Mil platôs: capitalismo e esquizofrenia. Volume 1. Tradução de Suely Rolnik. São Paulo: Editora 34, 1997. (Coleção TRANS). $4^{\text {a }}$ reimpressão 2008

FAUSTINI, Vinícius. Guia afetivo da periferia. Rio de Janeiro: Aeroplano, 2009.

GIL, José. A Imagem-nua e as pequenas percepções: estética metafenomenologia. Tradução de Miguel Serras Pereira. Lisboa: Relógio D’Água Editores, 1996.

GUATTARI, Félix. As três ecologias. Tradução Maria Cristina F. Bittencourt. Campinas: Papirus, 1990

GUATTARI, Félix. Revolução Molecular: pulsações políticas do desejo. São Paulo: Editora Brasiliense, 1987.

GUATTARI, Félix. Caosmose: um novo paradigma estético. Tradução de Ana Lúcia de Oliveira e Lúcia Cláudia Leão. São Paulo: Editora 34, 4a reimpressão, 2006

GUATTARI, Félix. Guattari, o paradigma estético. Entrevista concedida a Fernando Urribarri. In: Cadernos de Subjetividade / Núcleo de Estudos e Pesquisas da Subjetividade do Programa de Estudos Pós-Graduados em Psicologia Clínica da PUC-SP. - v. 1, n. 1- p. 29-34 - São Paulo, 1993

GUATTARI, Félix. Chaosmose. Galilée, Paris, 1992. 


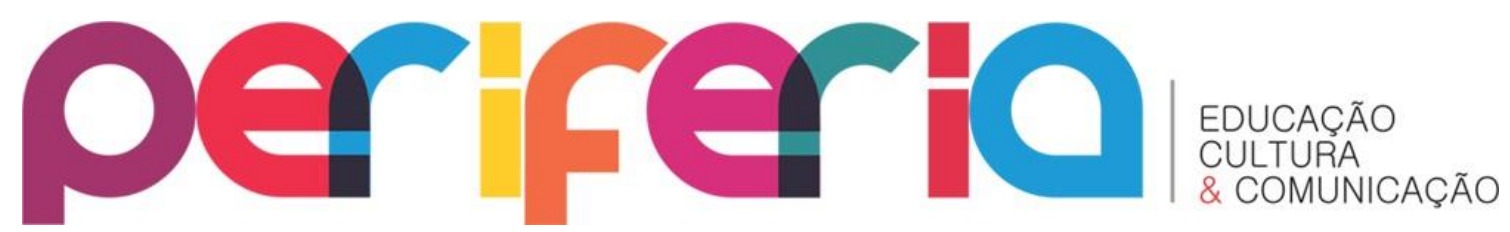

HARDT, Michael, NEGRI, Antonio. Multidão. Editora Record: Rio de Janeiro, 2005.

HOLANDA, Heloísa Buarque de. Prefácio. In FAUSTINI, Vinícius. Guia afetivo da periferia. Rio de Janeiro: Aeroplano, 2009.

IBGE, Site do. Disponível em:

http://www.ibge.gov.br/cidadesat/painel/painel.php?codmun=330170.

Acesso em: 15/02/2014

LACERDA, Stélio. Uma passagem pela Caxias dos anos 60. Duque de Caxias: ed. do autor, 2001.

MEDEIROS, Evandro. O delírio de Apolo: sobre teatro e cinema. Juiz de Fora (MG), Funalfa Edições, 2008. 130p.

PELBART, Peter Pál. Vida capital - ensaios de biopolítica. São Paulo:

Iluminuras, 2003

PELBART, Peter Pál. Um direito ao silêncio. In: Cadernos de Subjetividade / Núcleo de Estudos e Pesquisas da Subjetividade do Programa de Estudos PósGraduados em Psicologia Clínica da PUC-SP. - v. 1, n. , p. 41-48 - São Paulo, 1993 